\title{
PENGOLAHAN SAMPAH KERING DAN SAMPAH BASAH DI DESA GAMPANG KEC.PRAMBON KAB. SIDOARJO
}

\author{
${ }^{1}$ Achmad Fanani, ${ }^{2}$ Umrotul Aini, ${ }^{3}$ Persila Welafubun, dan Team KKN-PPM Desa Gampang \\ ${ }^{1,2,3}$ Fakutas Keguruan dan Ilmu Pendidikan, Universitas PGRI Adi Buana Surabaya \\ Email: ${ }^{2}$ Ainimujaer@gmail.com, ${ }^{3}$ Welafubunlala@gmail.com
}

\begin{abstract}
KKN or social action internship for advanced university students is a program from PGRI Adi Buana Surabaya University. This program is really useful because society can get the education from the students and the students can get the education from society too. The student was divided into groups and they had to live in the village for 1 month. Before the student went to the village, they had been accepted some materials and training. The students would work with their program. One program that is about very important is waste recycled. Rubbish recycled is the program that must be applied in the Gampang village, one of the village that had chosen by PGRI Adi Buana Surabaya University. As we know that rubbish is divided into two, such as dry waste and wet waste. Dry waste is the waste that cannot be recycled by microbes such as plastic, bottles, cardboard, and etc. Wet waste is the waste that can be recycled by microbes. There were two ways to recycled the waste, the first one was to make a composter to recycled wet waste and the second one was to make plastic bag to recycled dry waste. The method that the student had used to imply the program was observation, questionnaires and counseling. The result that the students got was the product that made by the society such as composter and plastic bag.
\end{abstract}

Key words: Dry Waste, Wet Waste, Recycled, Composter, Plastic Bag

\section{Pendahuluan}

Kegiatan kuliah kerja nyata merupakam kegiatan lapangan bagi mahasiswa yang menempuh bagian akhir dari program pendidikan SI.Program ini bersifat wajib bagi semua mahasiswa, karena universitas mempercayai bahwa program ini mampu mendorong empaty, mahasiswa dan dapat memberikan sumbangan bagi penyelesaian persoalan yang ada di masyarakat.Kegiatan ini menjadi bagian dari bentuk nyata kontribusi universitas bagi masyarakat, industri, pemerintah daerah dan kelompok yang ingin mandiri secara ekonomi maupun sosial. Dengan adanya program ini, masyarakat bisa memperoleh pengetahuan dari mahasiswa begitu pula sebaliknya sehingga akan mempunyai manfaat yang signifikan.

Universitas PGRI Adi Buana Surabaya adalah salah satu universitas yang menerapkan program tersebut.

Desa Gampang merupakan salah satu desa yang terdapat di kecamatan Prambon kabupaten Sidoarjo.Desa Gampang termasuk desa terkecil dengan jumlah penduduk \pm 2000 jiwa yang terdiri dari 1 dusun 8 RT dan 2 RW.Mayoritas penduduknya bekerja sebagai wirausaha/ home industry dan petani.Namun, terdapat juga berbagai profesidi desa Gampang, contohnya karyawan, PNS, dll.

Salah satu program KKN Universitas PGRI Adi Buana di desa Gampang terbagi dalam beberapa bidang 
dan salah satunya adalah bidang lingkungan yaitu pengolahan sampah kering dan sampah basah. Sampah merupakan suatu bahan yang terbuang atau dibuang dari sumber aktivitas manusia maupun proses alam yang belum memiliki nilai ekonomis.Sampah terbagi atas dua bagian yaitu sampah organic ( sampah basah ) dan sampah anorganik ( sampah kering).Sampah kering adalah sampah bersifat kering dan tidak dapat didaur oleh alam seperti kemasan plastic, botol dan kaleng bekas, dll.Sedangkan sampah basah merupakan kategori sampah yang mudah terurai oleh alam karena mempunyai tekstur yang bersifat basah yang dapat diurai oleh mikroba.Sedangkan Pengolahan sampah merupakan semua kegiatan yang bersangkut paut dengan timbulnya sampah, pengumpulan, transfer, pengolahan dan pemrosesan akhir dengan mempertimbangkan faktor kesehatan lingkungan, ekonomi yang erat kaitannya dengan respon masyarakat.

\section{METODE}

Awal kegiatan program KKN- PPM telah dimulai berupa koordinasi dengan kepala desa yang mewilayai lokasi tersebut, dengan diawali pertemuan dan diskusi bersama masyarakat sehingga menghasilkan data yang sebagian telah dituangkan dalam proposal.

Kegiatan sebelum mengabdi di masyarakatadalah perencanaanyang menyangkut pembekalan, berupa materi dan teknik sosialisasi utuk masyarakat,serta penyiapan perlengkapan pendukung selama berada di lokasi KKN-PPM.

Adapun metode yang digunakan dalam penerapan pengolahan sampah kering dan sampah basah di desa Gampang yaitu berupa :

1. Observasi

Observasi merupakan alat pengumpulan data yang dilakukan dengan cara mengamati dan mencatat secara sistimatik tentang jenis-jenis sampah yang ada di desa Gampang. Pada metode observasi ini, penulis secara langsung mengamati proses pengolahan sampah menjadi sesuatu hal yang bernilai. Data yang diperlukan dalam metode pengamatan ini adalah, mengamati secara langsung di lokasi, pelaksanaan proses kegiatan-kegiatan program mahasiswa universitas PGRI Adi Buana Surabaya di desa Gampang.

2. Kuisioner

Kuisioner merupakan instrument pengumpulan data atau informasi yang dioperasionalisasikan ke dalam bentuk item atau pertanyaan untuk memperoleh data dari sumbernya secara langsung.Pembagian kusioner yang dilakukan oleh mahasiswa KKN-PPM Universitas PGRI Adi Buana Surabaya melibatkan respoden, yaitu warga desa Gampang.Dalam satu kusioner terbagi dalam 2 program, yaitu pengolahan sampah kering yang berupa daur ulang kemasan platik menjadi bentuk kerajinan yang bernilai serta pengolahan sampah basah yang berupa pembuatan pupuk organik melalui komposter.

3. Penyuluhan

Penyuluhan merupakan proses pendidikan atau proses belajar yang berupa kegiatan penyebar luasan informasi dan penjelasan yang diberikan kepada masyarakat. Adapun materi yang diberikan pada saat penyuluhan yaitu:
a. jenis-jenis sampah,
b. manfaat sampah,
c. dampak pembuangan sampah sembarangan
d. proses pengolan sampah kering dan sampah basah.

\section{HASIL DAN PEMBAHASAN}

Di era globalisasi saat ini, sampah telah menjadi suatu hal yang sangat mengancam kehidupan seperti dalam bidang kesehatan. Dulu sampah merupakan limbah yang tidak memiliki nilai jual. Namun seiring berjalannya waktu, limbah dapat menjadi sesuatu yang mempunyai nilai. Sampah yang mempunyai nilai merupakan sampah yang telah dioleh menjadi suatu barang yang mempunyai manfaat.Seperti kerajinan, kompos, alat permainan, dll.Dengan adanya pengolahan sampah akan dapat mendorong perkembangan suatu Negara. sebelumnya, sampah terbagi menjadi 2 jenis yaitu sampah kering dan sampah basah. Sehingga mahasiswa Universitas PGRI Adi Buana 
Surabaya melakukan 2 program pengolahan sampah, yaitu:

1. Pengolahan sampah kering

Mengingat kandungan energi yang tinggi dari bahan plastik, maka potensi pemanfaatannya sebagai salah satu sumber energi memiliki prospek yang cukup bagus di masa mendatang.Dari sini bisa didapatkan dua keuntungan sekaligus yaitu mengurangi problem sampah dan juga menghasilkan energi yang bisa digunakan untuk mengurangi ketergantungan pada sumber energi konvensional.Produk yang dihasilkan sampah kering dapat berupa bonsai plastic, tas plastic, bunga plastic, dll. Tas plastic merupakan produk yang bernilai dan dapat digunakan kembali. Pembuatan tas plastic yang diterapkan oleh mahasiwa KKN-PPM Universitas PGRI Adi Buana Surabaya adalah tas dan dompet dari kemasan plastik. Adapun tahapan dalam pembuatan tas plastic adalah:

1) Alat dan bahan :

a. Bungkus kopi instan

b. Gunting

c. Penggaris

d. Jarum dan benang jahit

e. Furing/ kain polos

f. Risleting

2) Langkah-langkah :

a. Siapkan bungkus kopi instan merk apa saja. Lalu buang bagian atas dan bawah hingga kedua sisi terbuka.

b. Cuci bersih semua bungkus kopi lalu jemur hingga kering atau lap dengan kain.

c. Potong bungkus kopi menjadoi 2 bagian sama (tiap bagian $2 \mathrm{~cm}$ )

d. Lipat $1 \mathrm{~cm}$ ke dalam pada ujung atas dan bawah hingga lebarnya menjadf $=\mathrm{I} 2 \mathrm{~cm}$. Buat 1000 lipatan dari 500 bungkus atau sesuai ukuran yang diingikan.

e. Anyam keempat lipatan membentuk baling-baling.

f. Gabungkan baling-baling yang sudah terbentuk satu-persatu dan jangan lupa buat sudut tegak vertical agar bisa dianyam ke arah atas. Bila proses ini diabaikan maka anyaman hanya berbentuk seperti tikar.

g. Buat tali tas dengan lipatan tersisa membentuk segitiga. Lalu gabungkan segitiga yang satu dengan yang satu dengan yang lain (sebelum segitiga pertama ditutup dengan jahitan, masukkan dulu segitiga yang kedua, baru dijahit seperti mata rantai) Jika inginlebih mudah, gunakan tali kur atau sejenisnya untuk tali tas.

h. Setelah tali siap, jahit pada keranjang tas sesuai letak yang diinginkan

i. Lapisi bagian dalam tas dengan furing agak tebal atau kain polos agar lubang-lubangnya tertutupi. Lalu pasang risketing.

1. Pengolahan sampah basah

Sampah basah merupakan sampah yang mudah diurai oleh mikroba.mengingat banyaknya limbah rumah tangga di desa Gampang, maka mahasiswa universitar PGRI Adi Buana Surabaya memutuskan untuk mengolah limbah yang bersifat basah dan mudah terurai tersebut menjadi pupuk kompos yang bermanfaat dalam menyuburkan tanah. Sehingga dalam membuat pupuk kompos, digunakan bantuan komposter untuk membantu proses pembusukan. Komposter merupakan suatu alat bantu yang akan memudahkan dalam proses pembusukan sampah basah. Komposter dapat berupa tong sampah plastik atau kotak semen yang biasanya diletakkan di dalam atau di luar ruangan. Secara sederhana, komposter dapat dibuat sendiri menggunakan tong plastik bekas yang dimodifikasi. Ukuran komposter dapat disesuaikan dengan skala limbah.Untuk skala limbah keluarga kecil dapat menggunakan komposter berukuran 20-200 liter.Sementara itu, untuk skala besar seperti limbah rumah makan atau rumah sakit dapat menggunakan komposter 
berukuran $200 \quad$ liter.

Komposter memiliki instalasi untuk sirkulasi udara di dalamnya sehingga dapat membantu proses pengomposan dan mempercepat proses penguraian sampah. Selain itu, komposter juga mampu menjaga kelembapan dan suhu sehingga bakteri dan jasad renik dapat bekerja mengurai bahan organik secara optimal.Komposter juga memungkinkan aliran limbahterpisah dari material padat sehingga memudahkan untuk mendapatkan pupuk cair.Bersama dengan aktivator kompos seperti organik dekomposer, EM, dan Green Phoskko, sampah sisa rumah tangga dapat diubah menjadi kompos hanya dalam waktu 10-12 hari.Khusus untuk pembuatan pupuk cair dari limbah organik rumah tangga ini perlu digunakan bio-aktivator, seperti Propuri. Fungsi Propuri memang sama dengan aktivator lainnya, tetapi sedikit lebih praktis dalam penggunaannya. Penyemprotan menggunakan propuri dapat digantikan oleh pupuk cair dari hasil kompos yang telah dilakukan.

Pembuatan komposter yang diterapkan mahasiswa KKN-PPM Universitas PGRI Adi Buana Surabaya menghasilkan 2 jenis pupuk dalam 1 komposter, yaitu komposter yang menghasilkan pupuk organik cair dan komposter yang menghasilkan pupuk organik dalam bentuk tanah. Pada kedua jenis pupuk ini mempunyai manfaat yang sama, yaitu untuk menyuburkan tanaman. Adapun tahapan pembuatan komposter yang melibatkan alat dan bahan, yaitu:

1) Alat:
a. Gergaji
b. Meteran
c.Pensil
d. Lem paralon
e. Bor
f. Cutter
g. Gunting

2) Bahan:

a. 1 buah tong plastik ukuran 20 liter b. 2 buah pipa paralon dengan panjang $14 \mathrm{~cm}$ dan diameter 1 inch

c. 2 buah pipa paralon dengan panjang $10 \mathrm{~cm}$ dan diameter 1 inch

d. 1 buah pipa paralon dengan panjang $9 \mathrm{~cm}$ dan diameter 1 inch

e. 2 buah pipa paralon dengan panjang $1 \mathrm{~cm}$ dan diameter 1 inch

f. 2 buah sambungan pipa berbentuk $\mathrm{T}$

g. 1 buah keran plastic

h. Kasa plastik secukupnya

3) Langkah-langkah:

a. Buat dua lubang di sisi kanan dan kiri tong menggunakan bor. Untuk tong berukuran 20 liter, lubang berada di ketinggian 28 $\mathrm{cm}$ dari alas tong. Diameter lubang harus sama dengan diameter pipa paralon. Kedua lubang ini berfungsi sebagai lubang udara.

b. Buat satu lubang lagi di antara kedua lubang tong yang telah dibuat, posisi lubang ketiga ini harus lebih rendah dari lubang sebelumnya atau sekitar $10 \mathrm{~cm}$ dari alas tong.

c. Untuk pipa, potong-potong pipa berdiameter 1 inch sesuai ukuran yang diinginkan. Buat lubang-lubang kecil di badan pipa paralon $14 \mathrm{~cm}$ dan pipa paralon $10 \mathrm{~cm}$. Bungkus badan pipa yang berlubang tersebut dengan kasa plastik, hingga tertutup rapi.

d. Pasang keran plastik ke dalam lubang yang paling bawah (terletak di ketinggian $10 \mathrm{~cm}$ dari alas tong). Selalu gunakan seal yang telah tersedia agar tidak terjadi kebocoran. Kencangkan ulir keran plastik.

e. Untuk pipa, sambungkan pipa 9 $\mathrm{cm}$ dan kedua pipa $10 \mathrm{~cm}$ ke dalam sambungan $T$. Instalasi ini tidak perlu diberi perekat 
atau lem untuk memudahkan pelepasan apabila sewaktuwaktu terjadi kebocoran.

f. Tempatkan instalasi tersebut ke dalam komposter dengan salah satu pipa $10 \mathrm{~cm}$ mengarah ke lubang yang telah dipasangi keran plastik. Jadi, pipa $9 \mathrm{~cm}$ mengarah ke bawah dan pipa 10 $\mathrm{cm}$ lainnya mengarah ke atas.

g. Rangkai instalasi udara dengan menempatkan kedua pipa $14 \mathrm{~cm}$ ke dalam lubang bagian atas (terletak di ketinggian $28 \mathrm{~cm}$ dari alas tong).

h. Pasangkan sambungan $\mathrm{T}$ untuk setiap ujung pipa yang bertemu (antara kedua pipa $14 \mathrm{~cm}$ dan pipa $10 \mathrm{~cm}$ ).

i. Tutup kedua ujung pipa yang mencuat keluar sekitar $3 \mathrm{~cm}$ menggunakan kasa plastik. Potong kasa plastik membentuk lingkaran dengan diameter sekitar $1 \mathrm{~cm}$ lebih panjang dari diameter pipa.

j. Terakhir, tempelkan kasa lalu beri lem perekat di sekitar ujung pipa. Atur hingga tertutup rapi dengan penutup pipa. Gunting bagian kasa yang paling luar.

\section{PENUTUP}

Kuliah Kerjs Nyata (KKN)
merupakan bentuk pengabdian kepada
masyarakat oleh mahasiswa dengan
pendekatan lintas keilmuan dan sektoral
yang dilakukan pada waktu dan daerah
tertentu.Bentuk pengabdian yang dilakukan
terdiri dari beberapa macam, salah satunya
adalah dalam bidang lingkungan yaitu
pengolahan sampah kering dan sampah
basah menjadi sesuatu yang memiliki
nilai.Sampah kering adalah sampah bersifat
kering dan tidak dapat didaur oleh alam
seperti kemasan plastic, botol dan kaleng
bekas, dll.Sedangkan sampah basah
merupakan kategori sampah yang mudah
terurai oleh alam karena mempunyai tekstur
yang bersifat basah yang dapat diurai oleh
mikroba.

Dalam hal ini, mahasiswa menggunakan system pengolah sampah kering kemasan plastik yang akan diolah menjadi bentuk kerajinan yang mempunyai nilai. Contohnya: tas, dompet, dll. Sedangkan sampah basah menggunakan system pengolahan yang dibantu oleh alat, yaitu komposter. Komposter digunakan untuk mengolah sampah basah menjadi pupuk kompos organik yang akan menghasilkan 2 jenis pupuk, yaitu pupuk kompos organik cair dan pupuk kompos organik yang bersifat seperti tanah.

Pada kegiatan ini, mahasiswa mengolah sampah kering dan sampah basah menggunakan tahapan-tahapan yaitu dimulai dengan pengumpulan, transfer, pengolahan dan pemrosesan akhir dengan mempertimbangkan faktor kesehatan lingkungan, ekonomi yang erat kaitannya dengan respon masyarakat.

Saran dari kesimpulan diatas didapatkan hambatan dalam pelaksanaan kegiatan-kegiatan yang dilakukan tim devisi pengolahan sampah kering dan sampah basah yang dilakukan di desa Gamang. Dalam hal ini, mengenai keikutsertaan masyarakat dalam beberapa kegiatan yang telah dilaksanakan. Supaya lebih meningkatkan peran serta masyarakat dalam kegiatan- kegiatan yang telah dilaksanakan oleh tim KKN-PPN berikutnya agar kegiatan dapat berjalan dengan lebih baik dan dapat berguna untuk masyarakat.

Ucapan terima kasih

Puji syukur kami panjatkan kepada Tuhan Yang Maha Esa yang telah memberikan rahmat dan hidayah-Nya sehingga penyusunan artikel bidang kesehatan dengan judul "pengolahan sampah kering dan sampah basah di kec.Prambon kab.Sidoarjo" dapat diselesaikan dengan baik.Tidak lupa kami menghanturkan terima kasih kepada semua pihak yang telah mendukung kami selama kegiatan hingga akhir kegiatan. Antara lain kepada:

1. Bapak dekan

2. Bapak pembimbing lapangan

3. Bapak dan Ibu dosen Universitas PGRI Adi Buana Surabaya

4. Bapak kades 
5. Untuk kedua orang tua, yang telah mendukung dan tak pernah berhenti mendoakan.

6. Untuk seluruh perangkat desa Gampang yang telah mendukung selama kegiatan

7. Dan untuk saudaraku seluruh wargadesa Gampang yang telah mendukung dan ikut serta dalam setiap program yang telah dilaksanakan.

\section{DAFTAR PUSTAKA}

Zona kreatif. 2017. http://zonakreatif.com/caramembuat-tas-unik-dan-cantik-dari-plastik-bungkuskopi/

daun ijo. 2016. http://daunijo.com/membuatkomposter-mini-rumah-tangga-dari-ember-bekas/ genius edukasi. 2016.

https://panduanbertanam.blogspot.co.id/2016/04/car a-membuat-komposter-pupuk-organik.html

http://lintas

copas.blogspot.co.id/2012/03/yukmembuat-tascantik-dari-limbah.html

https://g8penyuluhan2016.wordpress.com/2016/03/3

1/artikel/ 